\title{
Removal of ethinylestradiol by adsorption process from aqueous solutions using entrapped activated carbon in alginate biopolymer: isotherm and statistical studies
}

\author{
Soha A. Abdel-Gawad ${ }^{1} \cdot$ Hossam M. Abdel-Aziz $^{1}$ (1) \\ Received: 7 September 2018 / Accepted: 12 April 2019 / Published online: 27 April 2019 \\ (c) The Author(s) 2019
}

\begin{abstract}
The aim of this study is to decrease ethinylestradiol contaminants using entrapped activated carbon in alginate biopolymer (AG-AC) by adsorption. Different ethinylestradiol concentrations were prepared in the laboratory. The effect of the operating parameter was studied by using different operating parameters (e.g., contact time, $\mathrm{pH}$, concentrations, adsorbent dose and stirring rate). The results were analyzed according to the Freundlich, Langmuir, Temkin and Dubinin-Radushkevich adsorption isotherms. The adsorption data are more appropriate by the Freundlich isotherm. Removal efficiency percentages for ethinylestradiol at $\mathrm{pH} 3$ using dose $10 \mathrm{~g} / \mathrm{L}$ of the adsorbent for $30 \mathrm{~min}$ with a fixed stirring rate at $100 \mathrm{rpm}$ were $\sim 84 \%$. The effect of different operating parameters was investigated using linear regression analysis, and they were found to account for more than $99 \%$ of the variables affecting the removal process.
\end{abstract}

Keywords Entrapped AG-AC · Removal of ethinylestradiol $\cdot$ Statistical and isotherm studies

\section{Introduction}

Ethinylestradiol is well known for its harmful impact on both aquatic life and humans, and therefore, it is already listed as seniority materials in a motion for a modulation of European Directives in the field of water policy. In view of these concerns, there have been many researchers across the earth evaluating the fate and removal of these contaminants in wastewater treatment processes, as the classical treatment procedures are not efficient in removing the chemicals to levels below their potentially no-effect concentrations (Ottosson et al. 1984, 1986; Lindberg et al. 1988, 1989; Ahrendt et al. 2009). Because of economic and technical drawbacks, ethinylestradiol recycling and removal technologies have not yet been widely adopted (Karapinar et al. 2004; Eskandarpour et al. 2006; Shi et al. 2011). Therefore, current researchers have been focused on modification methods that more adequately address contaminant removal from industrial wastewater (Karunya et al. 2015; Washington 2004; Murali et al. 2013). Activated carbon has a high adsorption capacity, but removing it from treated wastewater is not easy because of the dispersion of the powder (Kulkarni et al. 2013; Angin 2014; Goher et al. 2015). To overcome this issue and increase the removal efficiency through entrapment, activated carbon with other materials, such as alginate biopolymer (O'Connor et al. 2018) which helps in adsorption process, allows polluted aqueous solution to pass through it and be in contact with activated carbon (Siripattanakul and Khan 2010; Bezbaruah et al. 2014; Abdel-Gawad et al. 2016). It has become one of the best effective and economic wastewater treatment processes; thus, this method has agitated great concern during the latest years (Worch 2012; Faust and Aly 2013; Rashed 2013). The aim of this study is to explore the possibility of examining the probability of entrapped activated carbon in alginate biopolymer for the removal of ethinylestradiol from aqueous solutions. In supplement, the Freundlich, Dubinin-Radushkevich, Langmuir and Temkin isotherms are used to fit the data.

Hossam M. Abdel-Aziz

hossam_elywa@yahoo.com

1 Chemical Industries Development (CID) Company, Giza, Egypt 


\section{Experimental}

\section{Chemicals and reagents}

All chemicals used were of the analytical reagent grade and of highest purity, such as activated carbon [dried], ethinylestradiol $\left[\mathrm{C}_{20} \mathrm{H}_{24} \mathrm{O}_{2}\right.$, Zhejiang Xianju, dried], sodium alginate $\left[\left(\mathrm{C}_{6} \mathrm{H}_{7} \mathrm{NaO}_{6}\right) n\right.$, Qingdao Bright Moon], sodium hydroxide [ $\mathrm{NaOH}$, Riedel-de Haën], hydrochloric acid [ $\mathrm{HCl}$, Scharlau], sulfuric acid $\left[\mathrm{H}_{2} \mathrm{SO}_{4}\right.$, sever biotech], ethanol $96 \%\left[\mathrm{C}_{2} \mathrm{H}_{5} \mathrm{OH}\right.$, World co. for sub and med industries] and calcium chloride [ $\mathrm{CaCL}_{2}$, Fisher Scientific]. The change in $\mathrm{pH}$ was adjusted using $0.1 \mathrm{M} \mathrm{NaOH}$ and $0.1 \mathrm{M}$ $\mathrm{HCl}$ solutions.

\section{Instrumentation}

Millipore (Elix) UV-Milli-Q advantage $\mathrm{A} 10$ system Doubleddistilled water (DDW) from Millipore instrument was used throughout the study.

pH meter Jenway 3520 pH/mV/Temperature Meter, USA, was used for $\mathrm{pH}$ measurements.

UV/Vis spectrophotometer T70+UV/Vis spectrometer, PG instruments Ltd, was used for spectrophotometer measurements of the ethinylestradiol concentrations according to standard methods for the examination of water and wastewater (Eaton et al. 2013). It was also used for measuring color absorbance of samples at different wavelengths through scan spectrum curves.

Drier Most standard and reagent chemicals were dried before using.

Orbital shaker Lab shaker SSL1 Lab was used for effect of stirring rate studies.

\section{Methods}

\section{Preparation of adsorbent}

Alginate beads were prepared by adding $1 \mathrm{~g}$ of activated carbon to $2 \%(\mathrm{wt} / \mathrm{v})$ of sodium alginate solution, and the solution was stirred well. The mixture solution was added drop by drop to a $5 \%(\mathrm{wt} / \mathrm{v}) \mathrm{CaCl}_{2}$ solution. The alginate beads formed were taken out and washed several times to be used in the adsorption method.

\section{Batch adsorption studies}

Alginate beads with entrapped activated carbon were added to an aqueous ethinylestradiol solution $(5 \mathrm{mg} / \mathrm{L})$. Using different operating parameter: Effect of ( $\mathrm{pH}$, contact time, dose, concentrations and stirring rate) on ethinylestradiol solution, filter solution through glass fiber filter paper (WHATMAN 1441-125) and take specific amount of filtrate in volumetric flask, then ethinylestradiol concentration evaluated according to 25nd Edition of Standard Methods for the Examination of Water and Wastewater (Eaton et al. 2013). The removal percentages were calculated using the following equation:

Sorption $(\%)=\left(C_{\mathrm{o}}-C_{\mathrm{e}} / C_{\mathrm{o}}\right) \times 100$

where $C_{\mathrm{o}}$ is the initial concentration $(\mathrm{mg} / \mathrm{L})$ of ethinylestradiol in solution and $C_{\mathrm{e}}$ is the equilibrium concentration $(\mathrm{mg} / \mathrm{L})$ of ethinylestradiol in solution. The amount of ethinylestradiol adsorbed by entrapped activated carbon in alginate biopolymer was calculated using the following equation:

$q_{\mathrm{e}}(\mathrm{mg} / \mathrm{g})=\left[\left(C_{\mathrm{o}}-C_{\mathrm{e}}\right) \mathrm{V}\right] / \mathrm{m}$

where $q_{\mathrm{e}}$ is the equilibrium adsorption capacity $(\mathrm{mg} / \mathrm{g}), V$ is the volume of aqueous solution (L) and $m$ is the dry weight of the adsorbent $(\mathrm{g})$.

\section{Adsorption study}

\section{Freundlich isotherm}

The Freundlich isotherm (Freundlich 1906) is an empirical equation employed for describing heterogeneous adsorption surface and is given by:

$\ln q_{\mathrm{e}}=1 / n \ln C_{\mathrm{e}}+\ln K_{\mathrm{f}}$ where $n$ (dimensionless) and $K_{\mathrm{f}}\left[(\mathrm{mg} / \mathrm{g})(\mathrm{mg} / \mathrm{L})^{-1 / \mathrm{n}}\right]$ are Freundlich constants related to the adsorption intensity and adsorption capacity, respectively, and $\left(K_{\mathrm{f}}\right)$ and $(n)$ are evaluated by plotting $\ln q_{\mathrm{e}}$ and $\ln C_{\mathrm{e}}$.

\section{Langmuir isotherm}

Langmuir isotherm supposes monolayer coverage of adsorbate over a homogeneous surface of adsorbent (Langmuir 1918). The Langmuir linearized isotherm is given by the equation:

$C_{\mathrm{e}} / q_{\mathrm{e}}=1 /\left(K_{\mathrm{L}} q_{\max }\right)+C_{\mathrm{e}} / q_{\max }$

where $q_{\mathrm{e}}(\mathrm{mg} / \mathrm{g})$ is the mass of ethinylestradiol adsorbed per mass of adsorbent used, $C_{\mathrm{e}}(\mathrm{mg} / \mathrm{L})$ is equilibrium concentration of ethinylestradiol, $q_{\max }(\mathrm{mg} / \mathrm{g})$ is the maximum 
monolayer capacity of adsorption, and $K_{\mathrm{L}}(\mathrm{L} / \mathrm{mg})$ is the Langmuir constant related to binding sites affinity and adsorption energy. The plot of $C_{\mathrm{e}} / q_{\mathrm{e}}$ versus $C_{\mathrm{e}}$ is employed to generate the values of $q_{\max }$ and $K_{\mathrm{L}}$.

\section{Temkin isotherm}

The Temkin isotherm study has been chosen to estimate the adsorption potential of the adsorbed and adsorbent solution. This model contains a factor, which takes into respect the interactions of the membrane (adsorbent-adsorbate) and the aqueous solution ions (Temkin and Pyzhev 1940). The Temkin isotherm has been generally applied in the following equations:

$$
\begin{aligned}
Q_{\mathrm{e}} & =\left(R_{\mathrm{T}} / b\right) \ln \left(A_{\mathrm{T}} C_{\mathrm{e}}\right) \\
Q_{\mathrm{e}} & =\left(R_{\mathrm{T}} / b_{\mathrm{T}}\right) \ln A_{\mathrm{T}}+\left(R_{\mathrm{T}} / b\right) \ln C_{\mathrm{e}} \\
B & =R_{\mathrm{T}} / b_{\mathrm{T}}
\end{aligned}
$$

A linear expression of the Temkin equation is represented by:

$Q_{\mathrm{e}}=B \ln A_{\mathrm{T}}+\left(R_{\mathrm{T}} / b\right) \ln C_{\mathrm{e}}$

where $A_{\mathrm{T}}$ the equilibrium binding constant $(\mathrm{L} / \mathrm{g}), b_{\mathrm{T}}$ the adsorption constant $(\mathrm{J} / \mathrm{mol} \mathrm{K}), R$ universal gas constant $(8.314 \mathrm{~J} / \mathrm{mol} \mathrm{K}), T$ absolute temperature value $(298 \mathrm{~K}), B$ a constant related to the heat of sorption $(\mathrm{J} / \mathrm{mol})$.

\section{Dubinin-Radushkevich isotherm}

Dubinin-Radushkevich isotherm is generally applied for expressing the mechanism of adsorption with a distribution of a Gaussian energy onto a heterogeneous surface (Dubinin and Radushkevich 1947). The model has often successfully fitted the intermediate range of concentrations data well and high solute activities

$Q_{\mathrm{e}}=\left(Q_{\mathrm{s}}\right) \exp \left(-K_{\mathrm{ad}} \varepsilon^{2}\right)$

$\ln Q_{\mathrm{e}}=\ln \left(Q_{\mathrm{s}}\right)_{-}\left(K_{\mathrm{ad}} \varepsilon^{2}\right)$

where $Q_{\mathrm{e}}$ adsorbate amount in the adsorbent at equilibrium $(\mathrm{mg} / \mathrm{g}) ; Q_{\mathrm{s}}$ capacity of theoretical isotherm saturation $(\mathrm{mg} / \mathrm{g}) ; K_{\mathrm{ad}}$ Dubinin-Radushkevich isotherm constant $\left(\mathrm{mol}^{2} /\right.$ $\mathrm{kJ}^{2}$ ) and $\varepsilon$ Dubinin-Radushkevich isotherm constant. The approach was applied to distinguish the chemical and physical adsorptions of metal ions with its mean free energy; $E$ per molecule of adsorbate can be computed by the relationship

$E=\left[1 /\left(\sqrt{ } 2 B_{\mathrm{DR}}\right)\right]$

where $B_{\mathrm{DR}}$ is denoted as the isotherm constant.

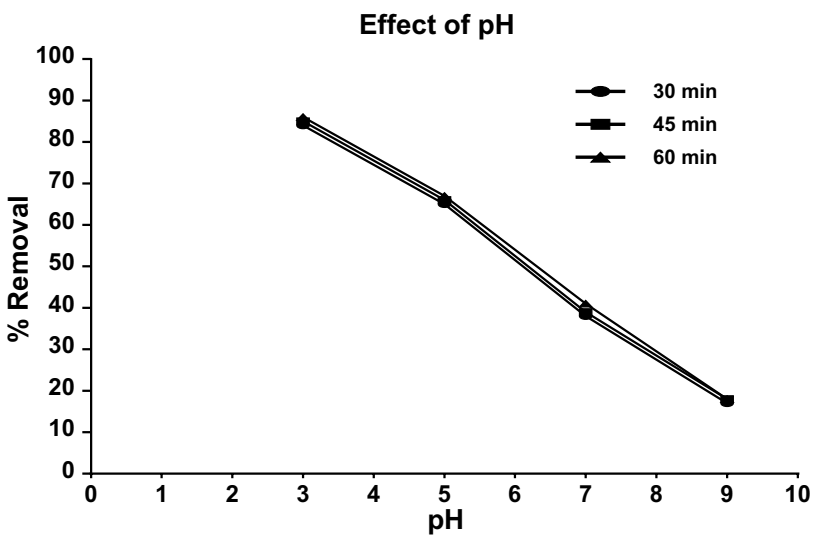

Fig. 1 Effect of $\mathrm{pH}$ on ethinylestradiol removal

\section{Results and discussion}

\section{Effect of $\mathrm{pH}$ value}

The influence of $\mathrm{pH}$ value on the amount of ethinylestradiol ions removed by entrapped activated carbon in alginate biopolymer from the aqueous solution was estimated by carrying out experiments with different $\mathrm{pH}$ values (3, 5, 7 and 9) at different contact times (30,45 and $60 \mathrm{~min})$, with removal efficiencies of $(84,65,38$ and $17 \%),(85$, 66,39 and 18\%) and (86, 76, 41 and 18\%), respectively; and plots of the $\mathrm{pH}$ against the percentage of the ethinylestradiol that was removed from the solution are shown in Fig. 1. The conditions used were: The ethinylestradiol concentration was $5 \mathrm{mg} / \mathrm{L}$, the adsorbent dose was $10 \mathrm{~g} / \mathrm{L}$, and the stirring rate was fixed at $100 \mathrm{rpm}$. The optimum $\mathrm{pH}$ for the removal was 3 . The $\mathrm{pH}$ of the aqueous solution plays a decisive role in affecting ethinylestradiol adsorption. In most systems, the absorption of anions such as ethinylestradiol decreases with the increase in $\mathrm{pH}$ and surface charge becomes more negative (Zhou et al. 2005; Eskandarpour et al. 2006). At the lower pH, adsorbents surface become protonated so the amount of ethinylestradiol adsorbed increased due to electrostatic attraction between positively charged surface and the negatively charged ethinylestradiol molecules. On the one hand, increasing the $\mathrm{pH}$ above 5 a negatively charged surface site on the adsorbent did not favor the adsorption of ethinylestradiol anions due to electrostatic repulsion (Zhou et al. 2005; Yao et al. 2011; Mohamed et al. 2015). Similar results were reported in the scientific literature for the adsorption of ethinylestradiol ( $\mathrm{Li}$ et al. 2007; Feng et al. 2010; Hartmann et al. 2014; Wang et al. 2014). 


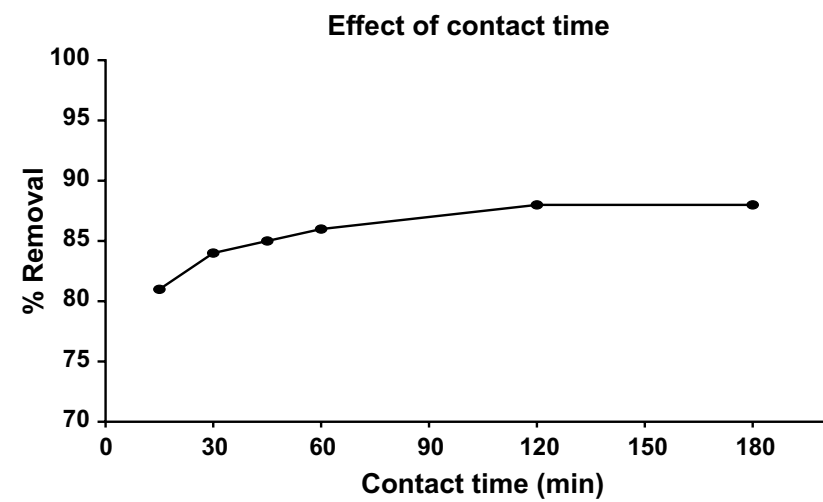

Fig. 2 Effect of contact time on ethinylestradiol removal

\section{Effect of contact time}

The contact time is another important operational factor that affects removal efficiency. The effect on ethinylestradiol removal was studied at different times $(15,30,45,60,120$ and $180 \mathrm{~min}$ ) using $10 \mathrm{~g} / \mathrm{L}$ of the adsorbent dose at $\mathrm{pH} 3$, and the stirring rate was fixed at $100 \mathrm{rpm}$. Ethinylestradiol concentration was $(5 \mathrm{mg} / \mathrm{L})$, and the removal percentages were $(81,84,85,86,88$ and $88 \%)$, as shown in Fig. 2. From the data given in Fig. 2, it is shown that an increase in contact time led to an increase in removal efficiency. Therefore, the ethinylestradiol uptake by entrapped activated carbon in alginate biopolymer was very rapid within the first $15 \mathrm{~min}$. After $15 \mathrm{~min}$, the uptake of ethinylestradiol progressively decreased with time. As the treatment time proceeded, the adsorbent sites had the inclination toward saturation. Equilibrium was established at $30 \mathrm{~min}$. Increase in time leads to increase in the contact between the ethinylestradiol ions and the larger surface area of the adsorbent as there are lots of free active sites for the adsorption (Amin 2008; Kulkarni et al. 2011; Rakholiya and Puranik 2012). Similar results were reported in the scientific literature for the adsorption of ethinylestradiol (Li et al. 2007, 2012; Hartmann et al. 2014; Wang et al. 2014; Mita et al. 2017).

\section{Effect of adsorbent dose}

Figure 3a depicts ethinylestradiol removal efficiency as a function of the adsorbent dose. The adsorbent doses were varied between 5 and $25 \mathrm{~g} / \mathrm{L}$. Other operational factors such as $\mathrm{pH}$, contact time and stirring rate were $3,30 \mathrm{~min}$ and $100 \mathrm{rpm}$, respectively. Ethinylestradiol concentration was $(5 \mathrm{mg} / \mathrm{L})$, and the removal percentages were $(80,84,87$, 89, 93\%), as shown in Fig. 3a. The optimum adsorbent dose for ethinylestradiol removal was found to be about $10 \mathrm{~g} / \mathrm{L}$, as shown in Fig. 3b. As expected, at high adsorbent dose the removal increased because of the increased adsorbent surface area; and the number of available adsorption sites
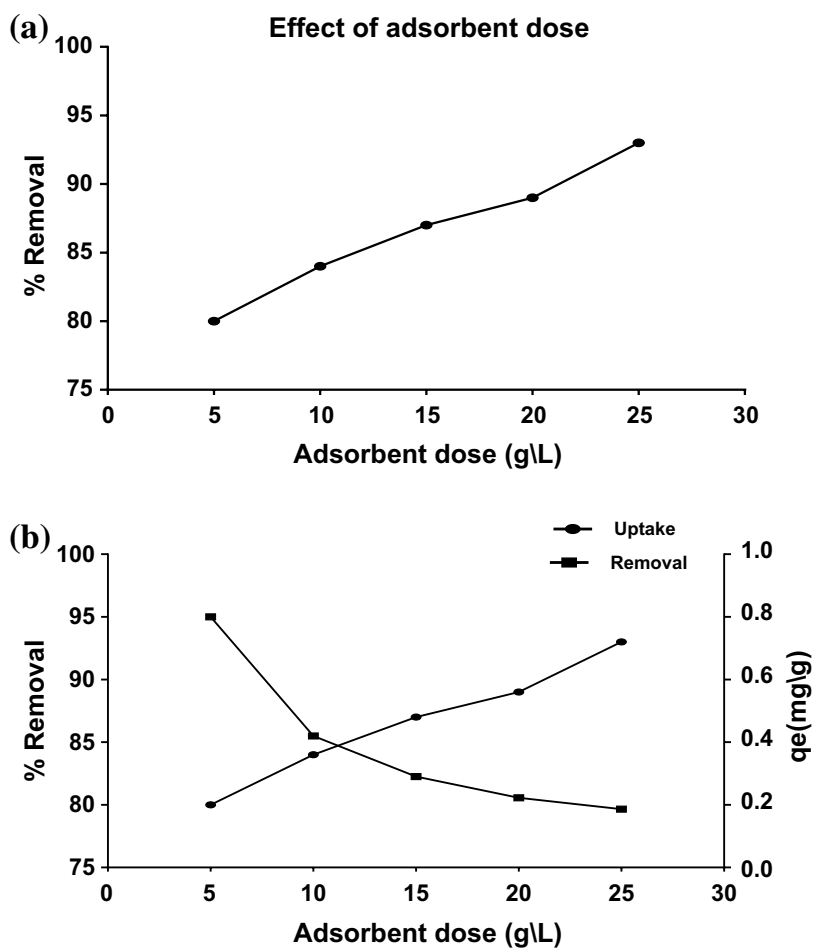

Fig. 3 a Effect of adsorbent dose on ethinylestradiol removal. b The optimum effective dose for ethinylestradiol removal

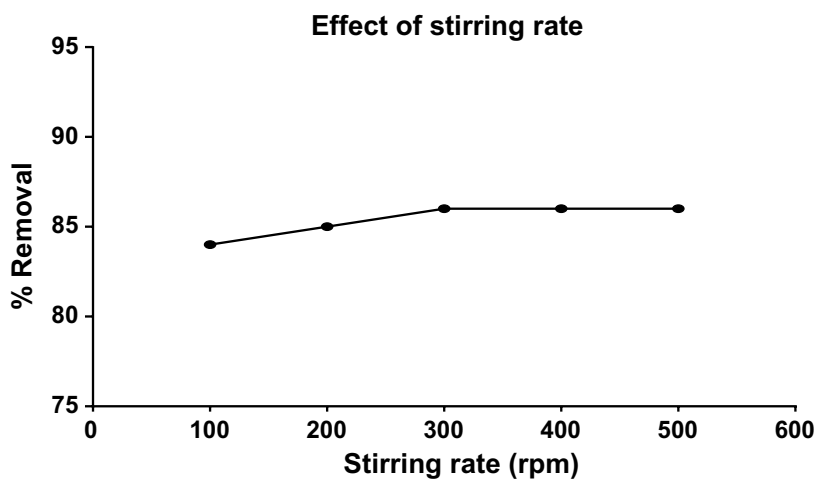

Fig. 4 Effect of stirring rate on ethinylestradiol removal

increased (Devi and Dahiya 2008; Samiksha and Mane 2015; Garg et al. 2015). Similar results were reported in the scientific literature for the adsorption of ethinylestradiol (Ifelebuegu 2012; Wang et al. 2014; Li et al. 2017).

\section{Effect of stirring rate}

Figure 4 depicts ethinylestradiol removal efficiency by entrapped activated carbon in alginate biopolymer as a function of stirring rate. The stirring rate was varied between 100 and $500 \mathrm{rpm}$. The other operational factors such as $\mathrm{pH}$, 


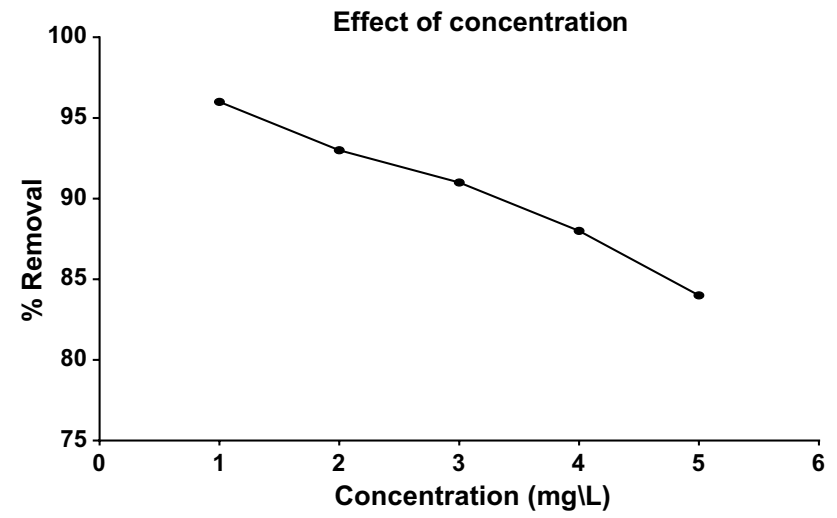

Fig. 5 Effect of concentration on ethinylestradiol removal

contact time and adsorbent dose were 3,30 min and $10 \mathrm{~g} / \mathrm{L}$, respectively. Ethinylestradiol concentration was $(5 \mathrm{mg} / \mathrm{L})$, and the removal percentages were $(84,84,84,85$ and $85 \%)$, as shown in Fig. 4. The optimum stirring rate for ethinylestradiol removal was found to be $100 \mathrm{rpm}$. The increase in stirring rate from 200 to $500 \mathrm{rpm}$ did not have a significant effect in the removal efficiency compared to $100 \mathrm{rpm}$. Increase in stirring rate enhanced the ethinylestradiol diffusion to the surface of the adsorbent (Devi and Dahiya 2008; Bernard et al. 2013).

\section{Effect of the concentration}

The effect of concentration of the aqueous solution on the percent ethinylestradiol reduction by entrapped activated carbon in alginate biopolymer was studied at various concentrations $(1,2,3,4$ and $5 \mathrm{mg} / \mathrm{L})$ at $\mathrm{pH} 3$, contact time $30 \mathrm{~min}$, stirring rate $100 \mathrm{rpm}$; adsorbent dose was $10 \mathrm{~g} / \mathrm{L}$, and the removal percentages were $(96,93,91,88$ and $84 \%)$, as shown in Fig. 5. At the beginning of adsorption process, the removal efficiency was higher because of the great number of available adsorption active sites of adsorbate molecules, but it decreased with time gradually due to the saturation and diminishing of these sites, which also caused a reduction in removal ratio (Zhou et al. 2005; Devi and Dahiya 2008).

\section{Adsorption isotherm studies for ethinylestradiol removal}

The sorption capacity of the adsorbent was predicted and evaluated by an adsorption isotherm study. The adsorption equilibrium data obtained at different initial ethinylestradiol concentrations were described using four different isotherm models, such as the Freundlich, Langmuir, Dubinin-Radushkevich (D-R) and Temkin equations which are the most commonly used isotherm applications for wastewater treatment, under predefined conditions of $\mathrm{pH}$, initial (a)

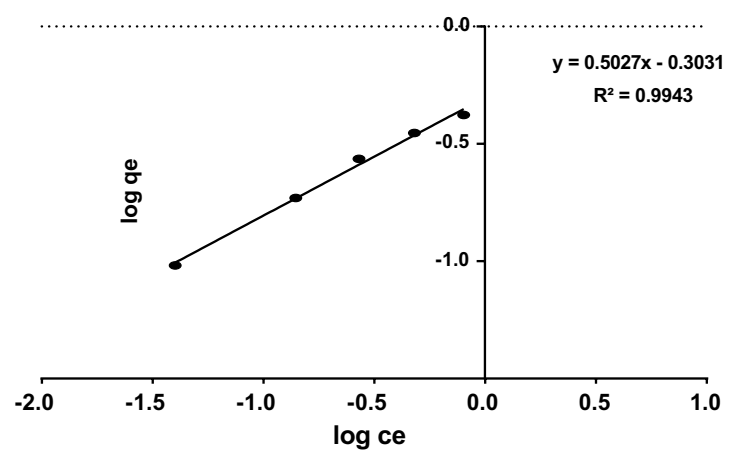

(b)
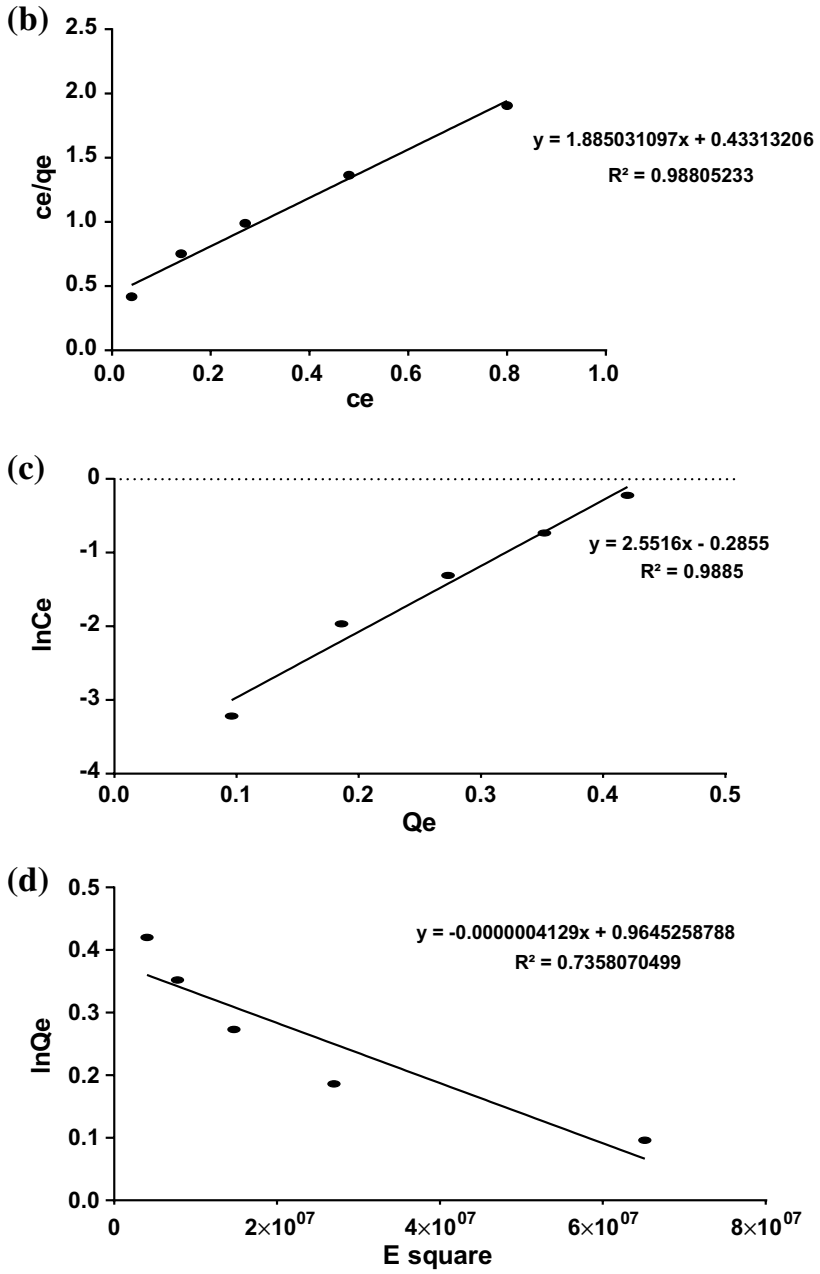

Fig. 6 a Freundlich adsorption isotherm for ethinylestradiol contributing component. b Langmuir adsorption isotherm for ethinylestradiol contributing component. c Temkin adsorption isotherm for ethinylestradiol contributing component. d Dubinin-Radushkevich adsorption isotherm for ethinylestradiol contributing component

concentrations, adsorbent dose, contact time and stirring rate (Ho and Chiang 2001; Foo and Hameed 2010; Adeogun and Balakrishnan 2015; Fola et al. 2016; Idowu et al. 2016). The acceptability and suitability of the isotherm equation to the equilibrium data were based on the values of the correlation 
Table 1 Isotherm parameters for the adsorption of ethinylestradiol

\begin{tabular}{llc}
\hline Isotherm name & Parameters & Values \\
\hline Freundlich & $K_{\mathrm{F}}\left[\mathrm{mg} / \mathrm{g}(\mathrm{mg} / \mathrm{L})^{-1 / \mathrm{n}}\right]$ & 2.01 \\
& $n$ & 1.989 \\
& $R^{2}$ & 0.994 \\
Langmuir & $Q_{\max }(\mathrm{mg} / \mathrm{g})$ & 0.53 \\
& $K_{\mathrm{L}}(\mathrm{L} / \mathrm{mg})$ & 0.816 \\
& $R^{2}$ & 0.988 \\
Temkin & $A_{\mathrm{T}}(\mathrm{L} / \mathrm{g})$ & 1.54082363 \\
& $b_{\mathrm{T}}(\mathrm{J} / \mathrm{mol} \mathrm{g} / \mathrm{mg})$ & 277.49339 \\
& $B$ & 8.9284 \\
& $R^{2}$ & 0.988 \\
Dubinin-Radushkevich & $Q_{\mathrm{s}}(\mathrm{mg} / \mathrm{g})$ & 1.46146 \\
& $K_{\mathrm{ad}}$ & $4.8 \mathrm{E}-09$ \\
& $R^{2}$ & 0.735 \\
\hline
\end{tabular}

Table 2 Variables entered/removed

\begin{tabular}{|c|c|c|c|}
\hline Model & Variables entered & Variables removed & Method \\
\hline 1 & $\begin{array}{l}\text { Concentration, dose, time, } \mathrm{pH} \text {, } \\
\text { stirring }^{\mathrm{a}}\end{array}$ & & Enter \\
\hline
\end{tabular}

Dependent variable: removal

${ }^{\mathrm{a}}$ All requested variables entered

Table 3 Model summary

\begin{tabular}{lllll}
\hline Model & $R$ & $R^{2}$ & Adjusted $R^{2}$ & SE of the estimate \\
\hline 1 & $0.998^{\mathrm{a}}$ & 0.995 & 0.994 & 1.27659 \\
\hline
\end{tabular}

aPredictors: (constant), concentration, dose, time, $\mathrm{pH}$, stirring

coefficients, $R^{2}$ estimated from linear regression of the least square fit statistic on Micro Math Scientist software. Figure $6 \mathrm{a}-\mathrm{d}$ represents the adsorption isotherms for the four models. The adsorption data were fitted well with the Freundlich and Langmuir isotherm models with the highest $R^{2}$ in their categories, as shown in Table 1 . The $n$ value $>1$ from Freundlich and maximum adsorption capacity of $0.53 \mathrm{mg} / \mathrm{g}$ from Langmuir with $K_{\mathrm{L}}<1$ obtained are indications that the adsorption is favorable on the investigated adsorbent; similar observation is reported in the literature (Veli and Alyüz 2007; Fola et al. 2016; Idowu et al. 2016).

\section{Statistical analysis}

The effect of the following variables on the removal process, e.g., $\mathrm{pH}$, contact time, dose, concentration, and stirring rate, has been studied using the entered method, where it was found that $R^{2}=0.995$, as shown in Tables 2 and 3. This means that the studied variables profanely occupy more than
Table 4 ANOVA

\begin{tabular}{lcrcll}
\hline Model & Sum of squares & $d f$ & Mean square & $F$ & Sig. \\
\hline Regression & 6745.596 & 5 & 1349.119 & 827.848 & $0.000^{\mathrm{a}}$ \\
Residual & 30.964 & 19 & 1.630 & & \\
Total & 6776.560 & 24 & & & \\
\hline
\end{tabular}

Dependent variable: removal

apredictors: (constant), concentration, dose, time, $\mathrm{pH}$, stirring

99\% of the total of the variables affecting the removal process as the standard error of the estimate is 1.27659 , which means that the percentage of error in this study is very low.

ANOVA program was applied, and the data are given in Table 4. This table showed the sum of squares and the effect of the whole model, where the model is considered successful if $P$ value is less than 0.05 .

\section{Table 5 (coefficients)}

The data given in Table 5 show the sum of squares, $P$ value and $T$ value for each variable. From the table, it can be inferred that all variables had an effect on the removal process except (stirring rate).

The effect of different operating parameters was investigated using linear regression analysis using statistical algorisms, where the obtained results support the practical results. By applying the $B$ values shown in the table, the removal equation can be deduced:

$$
\begin{aligned}
R \%= & 125.294+(-10.994) X 1+(0.037) X 2+(0.584) X 3 \\
& +(0.002) X 4+(-3.087) X 5
\end{aligned}
$$

where $X 1$ is the effect of $\mathrm{pH}(3,5,7$ and 9), $X 2$ is the effect of contact time $(15,30,60,120$ and $180 \mathrm{~min}), X 3$ is the effect of adsorbent dose $(5,10,15,20$ and $25 \mathrm{~g} / \mathrm{L}), X 4$ is the effect of stirring rate $(100,200,300,400$ and $500 \mathrm{rpm})$ and $X 5$ is the effect of concentration $(1,2,3,4$ and $5 \mathrm{mg} / \mathrm{L})$.

\section{Conclusions}

In this study, the aqueous ethinylestradiol concentration can be eliminated by entrapped activated carbon in alginate biopolymer, which is capable of ethinylestradiol removal from aqueous solution. Various operating parameters of ethinylestradiol removal efficiency were investigated and optimized. Removal was affected by the experimental parameters such as contact time, dose, $\mathrm{pH}$, stirring rate, concentration. Maximum ethinylestradiol removal was observed at the $\mathrm{pH}$ value of 3. Ethinylestradiol removal efficiency between 96 and $84 \%$ was achieved after using different ethinylestradiol 
Table 5 Coefficients

\begin{tabular}{|c|c|c|c|c|c|c|}
\hline \multirow[t]{2}{*}{ Model } & & \multicolumn{2}{|c|}{ Unstandardized coefficients } & \multirow{2}{*}{$\begin{array}{l}\text { Standardized coef- } \\
\text { ficients } \\
\text { Beta }\end{array}$} & \multirow[t]{2}{*}{$t$} & \multirow[t]{2}{*}{ Sig. } \\
\hline & & $B$ & SE & & & \\
\hline \multirow[t]{6}{*}{1} & (Constant) & 125.294 & 1.511 & & 82.905 & 0.000 \\
\hline & $\mathrm{pH}$ & -10.994 & 0.186 & -0.947 & -59.117 & 0.000 \\
\hline & Time & 0.037 & 0.008 & 0.076 & 4.655 & 0.000 \\
\hline & Dose & 0.584 & 0.071 & 0.133 & 8.265 & 0.000 \\
\hline & Stirring & 0.002 & 0.003 & 0.014 & 0.831 & 0.416 \\
\hline & Concentration & -3.087 & 0.266 & -0.191 & -11.623 & 0.000 \\
\hline
\end{tabular}

Dependent variable: removal

concentrations $(1,2,3,4$ and $5 \mathrm{mg} / \mathrm{L})$ with $10 \mathrm{~g} / \mathrm{L}$ of encapsulated activated carbon in alginate biopolymer, stirring rate $100 \mathrm{rpm}$ and contact time $30 \mathrm{~min}$. When the entrapped activated carbon in alginate biopolymer dose was increased from 5 to $25 \mathrm{mg} / \mathrm{L}$, the removal of ethinylestradiol increased by $13 \%\left(C_{0}=5 \mathrm{mg} / \mathrm{L}\right)$. The adsorption data were fitted well with the Freundlich isotherm model with the highest value $\left(R^{2}=0.99\right)$. The entrapped activated carbon in alginate biopolymer can be a cost-effective alternative and can lead to success in wastewater treatment and produce high-quality treated effluent.

Open Access This article is distributed under the terms of the Creative Commons Attribution 4.0 International License (http://creativeco mmons.org/licenses/by/4.0/), which permits unrestricted use, distribution, and reproduction in any medium, provided you give appropriate credit to the original author(s) and the source, provide a link to the Creative Commons license, and indicate if changes were made.

\section{References}

Abdel-Gawad SA, Baraka AM, El-Shafei MM, Mahmoud AS (2016) Effects of nano zero valent iron and entrapped nano zero valent iron in alginate polymer on poly aromatic hydrocarbons removal. J Environ Biotechnol Res 5:18-28

Adeogun AI, Balakrishnan RB (2015) Kinetics, isothermal and thermodynamics studies of electrocoagulation removal of basic dye rhodamine B from aqueous solution using steel electrodes. Appl Water Sci 7:1-13

Ahrendt H-J, Makalová D, Parke S, Mellinger U, Mansour D (2009) Bleeding pattern and cycle control with an estradiol-based oral contraceptive: a seven-cycle, randomized comparative trial of estradiol valerate/dienogest and ethinyl estradiol/levonorgestrel. Contraception 80:436-444

Amin NK (2008) Removal of reactive dye from aqueous solutions by adsorption onto activated carbons prepared from sugarcane bagasse pith. Desalination 223:152-161

Angin D (2014) Production and characterization of activated carbon from sour cherry stones by zinc chloride. Fuel 115:804-811

Bernard E, Jimoh A, Odigure J (2013) Heavy metals removal from industrial wastewater by activated carbon prepared from coconut shell. Res J Chem Sci 2231:606X
Bezbaruah A, Almeelbi TB, Quamme M, Khan E (2014) Calcium-alginate entrapped nanoscale zero-valent iron (nzvi). Google patents

Devi R, Dahiya R (2008) COD and BOD removal from domestic wastewater generated in decentralised sectors. Biores Technol 99:344-349

Dubinin M, Radushkevich L (1947) Equation of the characteristic curve of activated charcoal. Chem Zent 1:875

Eaton AD, Clesceri LS, Greenberg AE, Franson MAH (2013) Standard methods for the examination of water and wastewater. Am Public Health Assoc 1015:49-51

Eskandarpour A, Sassa K, Bando Y, Okido M, Asai S (2006) Magnetic removal of phosphate from wastewater using schwertmannite. Mater Trans 47:1832

Faust SD, Aly OM (2013) Adsorption processes for water treatment. Elsevier, Amsterdam

Feng Y, Zhang Z, Gao P, Su H, Yu Y, Ren N (2010) Adsorption behavior of EE 2 (17 $\alpha$-ethinylestradiol) onto the inactivated sewage sludge: kinetics, thermodynamics and influence factors. J Hazard Mater 175:970-976

Fola AT, Idowu AA, Adetutu A (2016) Removal of $\mathrm{Cu}_{2+}$ from aqueous solution by adsorption onto quail eggshell: kinetic and isothermal studies. J Environ Biotechnol Res 5:1-9

Foo K, Hameed B (2010) Insights into the modeling of adsorption isotherm systems. Chem Eng J 156:2-10

Freundlich H (1906) Over the adsorption in solution. J Phys Chem 57:e470

Garg K, Rawat P, Prasad B (2015) Removal of Cr(VI) and COD from electroplating wastewater by corncob based activated carbon. Int J Water Wastewater Treat 1. https://www.researchgate.net/profi le/Krishan_Garg3/publication/281271146_Removal_of_Cr_VI_ and_COD_from_Electroplating_Wastewater_by_Corncob_Based Activated_Carbon/links/55ddb43a08ae7983897cf425.pdf

Goher ME, Hassan AM, Abdel-Moniem IA, Fahmy AH, Abdo MH, El-sayed SM (2015) Removal of aluminum, iron and manganese ions from industrial wastes using granular activated carbon and Amberlite IR-120H. Egypt J Aquat Res 41:155-164

Hartmann J, Beyer R, Harm S (2014) Effective removal of estrogens from drinking water and wastewater by adsorption technology. Environ Process 1:87-94

Ho Y, Chiang C (2001) Sorption studies of acid dye by mixed sorbents. Adsorption 7:139-147

Idowu AA, Sunday O, Olateju KS (2016) Removal of Mn(II) from aqueous solution by Irvingia gabonensis immobilized Aspergillus sp. TU-GM14: isothermal, kinetics and thermodynamic studies. J Environ Biotechnol Res 3:1-11

Ifelebuegu AO (2012) Removal of steriod hormones by activated carbon adsorption-kinetic and thermodynamic studies. J Environ Prot 3:469 
Karapinar N, Hoffmann E, Hahn HH (2004) Magnetite seeded precipitation of phosphate. Water Res 38:3059-3066

Karunya S, Feroz S, Al Harassi S, Sakhile K (2015) Treatment of Oman pharmaceutical industry wastewater using low cost adsorbents. J Multi Eng Sci Technol 2(3):339-341

Kulkarni SJ, Patil SV, Tapre RW, Kadu SS (2011) Studies on adsorption for phenol removal by using activated carbon in batch and fluidized bed adsorption. Inst Tech 382:8-10

Kulkarni SJ, Tapre RW, Patil SV, Sawarkar MB (2013) Adsorption of phenol from wastewater in fluidized bed using coconut shell activated carbon. Proc Eng 51:300-307

Langmuir I (1918) The adsorption of gases on plane surfaces of glass, mica and platinum. J Am Chem Soc 40:1361-1403

Li J, Zhou B, Shao J, Yang Q, Liu Y, Cai W (2007) Influence of the presence of heavy metals and surface-active compounds on the sorption of bisphenol A to sediment. Chemosphere 68:1298-1303

Li Z, Dvorak B, Li X (2012) Removing 17 $\beta$-estradiol from drinking water in a biologically active carbon (BAC) reactor modified from a granular activated carbon (GAC) reactor. Water Res 46:2828-2836

Li Q, Ma X, Gao N, Chu W (2017) Removal of 17 a-ethynylestradiol from aqueous solutions by a hybrid PAC/UF process. Water SA 43:116-121

Lindberg U-B, Enk L, Crona N, Silfverstolpe G (1988) A comparison of the effects of ethinyl estradiol and estradiol valerate on serum and lipoprotein lipids. Maturitas 10:343-352

Lindberg U, Crona N, Stigendal L, Teger-Nilsson A, Silfverstolpe G (1989) A comparison between effects of estradiol valerate and low dose ethinyl estradiol on haemostasis parameters. Thromb Haemost 61:65-69

Mita L, Forte M, Rossi A, Adamo C, Rossi S, Mita DG, Guida M, Portaccio M, Godievargova T, Yavour I (2017) Removal of 17- $\alpha$ ethinylestradiol from water systems by adsorption on polyacrylonitrile beads: isotherm and kinetics studies. Peertechz J Environ Sci Toxicol 2:48-58

Mohamed E, Selim A, Selim M, Abukhadra MR (2015) Modeling and optimizations of phosphate removal from aqueous solutions using synthetic zeolite Na-A. J Mater Sci Chem Eng 3:15

Murali K, Karuppiah P, Nithish M, Kumar SS, Raja VS (2013) COD reduction using low cost biosorbent as part of cleaner production. Int J Sci Res Publ 3:1-3

O’Connor D, Hou D, Ok YS, Song Y, Sarmah A, Li X, Tack FM (2018) Sustainable in situ remediation of recalcitrant organic pollutants in groundwater with controlled release materials: a review. J Controlled Release

Ottosson U, Lagrelius A, Rosing U, Von Schoultz B (1984) Relative fatty acid composition of lecithin during postmenopausal replacement therapy - a comparison between ethinyl estradiol and estradiol valerate. Gynecol Obstet Invest 18:296-302

Ottosson U, Carlström K, Johansson B, Von Schoultz B (1986) Estrogen induction of liver proteins and high-density lipoprotein cholesterol: comparison between estradiol valerate and ethinyl estradiol. Gynecol Obstet Invest 22:198-205

Rakholiya VV, Puranik S (2012) COD reduction using modifying industrial effluent treatment flowsheet and low cost adsorbent as a part of cleaner production. Adv Appl Sci Res 3:1279-1291

Rashed MN (2013) Adsorption technique for the removal of organic pollutants from water and wastewater. INTECH Open Access Publisher, New York

Samiksha G, Mane S (2015) Reduction of chemical oxygen demand by using coconut shell activated carbon and sugarcane bagasse fly ash. Int J Sci Res 4:642-645

Shi Z-L, Liu F-M, Yao S-H (2011) Adsorptive removal of phosphate from aqueous solutions using activated carbon loaded with Fe(III) oxide. New Carbon Mater 26:299-306

Siripattanakul S, Khan E (2010) Fundamentals and applications of entrapped cell bioaugmentation for contaminant removal. In: Emerging environmental technologies, vol II. Springer, pp 147-169

Temkin M, Pyzhev V (1940) Kinetics of ammonia synthesis on promoted iron catalysts. Acta Physiochim URSS 12:217-222

Veli S, Alyüz B (2007) Adsorption of copper and zinc from aqueous solutions by using natural clay. J Hazard Mater 149:226-233

Wang Y, Hu L, Wang Q, Lu G, Li Y (2014) Adsorption behaviors of $17 \alpha$-ethinylestradiol in sediment-water system in northern Taihu Lake, China. Sci World J 2014:1-6

Washington E (2004) DC: "primer for municipal waste water treatment systems." Document no. EPA 832-R-04-001

Worch E (2012) Adsorption technology in water treatment: fundamentals, processes, and modeling. Walter de Gruyter, Berlin

Yao Y, Gao B, Inyang M, Zimmerman AR, Cao X, Pullammanappallil P, Yang L (2011) Removal of phosphate from aqueous solution by biochar derived from anaerobically digested sugar beet tailings. J Hazard Mater 190:501-507

Zhou A, Tang H, Wang D (2005) Phosphorus adsorption on natural sediments: modeling and effects of $\mathrm{pH}$ and sediment composition. Water Res 39:1245-1254

Publisher's Note Springer Nature remains neutral with regard to jurisdictional claims in published maps and institutional affiliations. 